\title{
Educação Patrimonial e História da Educação: contribuições para a formação de professores
}

\author{
Claudia Maria Soares Rossi*
}

\begin{abstract}
Resumo
Este artigo tem como proposta realizar uma discussão sobre as possibilidades de articulação entre o ensino da História da Educação e o da Educação Patrimonial, sabendo da importância da construção de uma consciência histórica no contexto de formação de professores. São discutidos conceitos de educação, história, memória, educação patrimonial, identidade e patrimônio. Este trabalho retrata a Educação Patrimonial como um processo de trabalho educacional centrado no Patrimônio Cultural como fonte de conhecimento e enriquecimento individual e coletivo, construindo uma proposta de ensino de história da educação baseada na pesquisa e na reflexão, desmistificando o senso comum e ajudando os professores a perceberem a escola e o fazer educacional como patrimônios culturais. Esta é uma pesquisa qualitativa e a metodologia utilizada foi a revisão bibliográfica pautada no referencial teórico de autores que tratam da Educação Patrimonial. História da Educação, Currículo e Formação de Professores.
\end{abstract}

Palavras-chave: Educação Patrimonial; História da Educação; Formação de Professores.

\section{Patrimonial Education and history of education: contributions for the teachers education}

\begin{abstract}
This article aims to hold a discussion on the possibilities of coordination between the teaching of History of Education and the Heritage Education, knowing the importance of building a historical consciousness in the context of teacher education. Concepts of education, history, memory, heritage education, identity and equity are discussed. This work depicts the heritage education as a process of educational work focused on Cultural Heritage as a source of knowledge and individual and collective enrichment, building a proposal for teaching history based on research and reflection on education, demystifying common sense and helping teachers realize the school and the educational and cultural heritages do. This is a qualitative study and the methodology used was the literature review guided the theoretical framework of writers on the Heritage Education. History of Education, Curriculum and Teacher Education

Keywords: Heritage Education; History of Education; Teacher Training.
\end{abstract}

\section{Introdução}

É claro que para mim a vida foi a mestra da história, na medida em que eu, como seu discípulo, tenha sido capaz de fazer da história a mestra da vida: sem a tremenda experiência de vida que nos dá o nosso século e a sua cultura, não teríamos a capacidade de ler nada naqueles antigos testamentos. Mas, agora é possível como diz o velho adágio, a história seja mestra da vida? O que nos pode ensinar? A renovar conteúdos e experimentar novas metodologias? A competência nunca fez mal. Ou a retomar antigas sátiras? (...) Ou a repropor Utopias? (MANACORDA, 2010, p. 431).

O objetivo deste artigo é discutir as possíveis articulações entre o campo do ensino da História da Educação e o da Educação Patrimonial, sabendo que através da formação de uma consciência histórica, os professores poderão compreender melhor os modos de construção de identidades e de produção da memória coletiva, reviver como a sociedade se desenvolveu e influenciou a educação e ainda aprender a incluir grupos, pessoas e práticas culturais no campo do patrimônio.

Uma das motivações para a realização do presente trabalho foi a leitura e o estudo do Livro História da Educação: Da Antiguidade aos nossos dias, de Mario Alighiero Manacorda (2010), na sua $13^{a}$ edição, indicado na disciplina História Social da Docência e sua dinâmica na atualidade que foi ministrada pelo prof. Vanderlei Barbosa, no Mestrado Profissional em Educação da Universidade Federal de Lavras, do qual sou aluna.

Ao estudar o livro indicado, que busca retratar a história da educação em tempos e culturas diferentes, podem-se perceber quantas fontes e patrimônios históricos serviram de referencial para a pesquisa do historiador e para que a sua narrativa fosse tão rica em detalhes sobre culturas, valores,

\footnotetext{
*Endereço Eletrônico: claudiamariasoares@hotmail.com
} 
ideologias, trazendo a reflexão sobre a importância de conhecer o passado, para entendermos o presente e organizarmos melhor o futuro, sendo este um dos princípios da Educação Patrimonial.

A função do narrador histórico é procurar sentido nos atos humanos, buscando neles vínculos com os acontecimentos que ecoam no presente. Seu valor não está em oferecer uma imagem do passado, tirando sua autenticidade, mas, transformá-lo em uma experiência política única que possa renovar o futuro com seu reconhecimento no presente. Um sentido histórico só pode ser apreendido se o acontecimento passado for interrogado (LOPES, 2012, p. 03).

Tratando da História da Educação, como poderíamos conhecê-la sem entender os atos humanos que a compuseram? Como questionar os feitos da educação contemporânea sem interrogar o passado e suas construções? Mais do que trazer a imagem do passado, ao se trabalhar com a História da Educação, torna-se essencial a discussão em busca do entendimento dos processos de renovação e transformação que foram acontecendo ao longo dos tempos e do que ainda permanece, persiste, parece arraigado nos feitos de hoje.

A Educação Patrimonial, como uma metodologia aplicada em trabalhos educacionais, foi introduzida pela museóloga Maria de Lourdes Parreiras Horta a pouco menos de trinta anos, precisamente em 1983 , por ocasião do $1^{\circ}$ Seminário sobre o "Uso Educacional de Museus e Monumentos", organizado pelo Museu Imperial, em Petrópolis, no Rio de Janeiro (HORTA et al., 1999, p. 05). Porém, o termo Educação Patrimonial surgiu na Inglaterra com o nome de heritage education (educação para o patrimônio), constituindo-se como uma prática metodológica em torno dos patrimônios e que no Brasil, tem sido incentivada desde 1937 pelo IPHAN - Instituto do Patrimônio Histórico e Artístico Nacional. É o IPHAN que apresenta uma interessante definição de Educação Patrimonial:

Toda vez que as pessoas se reúnem para construir e dividir novos conhecimentos investigam pra conhecer melhor, entender e transformar a realidade que nos cerca, estamos falando de uma ação educativa. Quando fazemos tudo isso levando em conta alguma coisa que tenha relação ao com nosso patrimônio cultural, então estamos falando de Educação Patrimonial! O patrimônio cultural é o conjunto de manifestações, realizações e representações de um povo, de uma comunidade. Ele está presente em todos os lugares e atividades: nas ruas, em nossas casas, em nossas danças e músicas, nas artes, nos museus e escolas, igrejas e praças. Nos nossos modos de fazer, criar e trabalhar. Nos livros que escrevemos, na poesia que declamamos, nas brincadeiras que organizamos, nos cultos que professamos. Ele faz parte de nosso cotidiano e estabelece as identidades que determinam os valores que defendemos. É ele que nos faz ser o que somos (IPHAN, 2013).

De acordo com a citação acima, a construção da História da Educação acontece pelas formas de representação que as pessoas dão aos fatos e pela maneira como elas manifestam suas formas de fazer, trabalhar, ensinar, através dos registros documentais que vão deixando ou através das histórias que vão contando.

Tendo como base o pensamento citado acima, surge a pergunta que norteia este trabalho de pesquisa: De que forma os princípios da Educação Patrimonial podem ajudar no ensino da História da Educação?

A hipótese é de que a Educação Patrimonial, desenvolvida nos trabalhos que tratam do ensino da historia da educação, pode ajudar a desmistificar o senso comum fazendo com que os professores, os estudantes de licenciatura, percebam a escola e o fazer educacional como patrimônios culturais pertencentes à história de cada um que se compromete com a educação.

Mediante esse questionamento, este trabalho será desenvolvido em duas partes. A primeira parte traz alguns conceitos de Educação, Patrimônio, Identidade, Memória e Patrimônio. A segunda parte procura retratar o ensino da História da Educação e a Educação Patrimonial relacionadas ao processo de formação de professores.

Este artigo é resultado de uma pesquisa qualitativa e a metodologia utilizada foi a revisão bibliográfica pautada no referencial teórico de autores que tratam da Educação Patrimonial como Horta (1999), Pelegrini (2009), Possoli (2008), Silveira e Bonato (2008), Soares (2003), Oliveira (2010), Chaves (2013), além de Manacorda (2010), Arroyo (2013), Freire (1991) e Martinho (2000), no que se refere à História da Educação, Currículo e Formação de Professores.

O presente artigo, que trata da Educação Patrimonial, faz parte de um recorte bibliográfico no conjunto de escritos que integram uma dissertação de mestrado em construção. 


\section{Educação, História, Identidade, Patrimônio}

(...) a felicidade humana será possível somente na medida e nas formas em que o procede da incessante luta dos homens contra a natureza para humanizá-la, humanizando a si mesmos, permitirá atingi-la. Desta luta também faz parte a consciência histórica, o voltar-se atrás para considerar o quanto as coisas vêm de longe para prosseguir à frente, bem mais longe (MANACORDA, 2010, p. 426-427).

O pensamento de Manacorda (2010) traz à tona a reflexão sobre a importância da consciência histórica na busca pela humanização, pois sem ela o homem não é capaz de entender que é um ser histórico, que cria, que sofre influências, que compartilha, que pode comprometer com a transformação.

Paulo Freire (1991), pensador contemporâneo, conceitua a Educação como um processo humanizante, social, político, ético, histórico, cultural e baseado nesta concepção é que a educação tem buscado ser um instrumento que provoca a emancipação do sujeito e a transformação da realidade social.

Somente um ser que é capaz de sair de seu contexto, de distanciar-se dele para ficar com ele; capaz de admirá-lo para, objetivando-o, transformá-lo pela sua própria criação; um ser que é e está sendo no tempo que é o seu, um ser histórico, somente este é capaz, por tudo isto, de comprometer-se. Além disso, somente este ser é, já em si, um compromisso. Este ser é o homem (FREIRE, 1991, p. 15).

Fica evidente que o trabalho educacional que é voltado para a construção de sujeitos sociais que buscam a transformação da realidade que os cerca, deve proporcionar, primeiramente, a esses sujeitos a oportunidade de conhecerem a si mesmos, pois a auto identidade insere o indivíduo em um grupo social, contexto cultural e aponta seu papel na comunidade diferenciando o "eu" dos "outros".

A história, fala de processos e de transformações, de luzes e sombras sempre em movimento, de estruturas e de conjunturas, de contrastes e de semelhanças, num panorama complexo em que nos situamos como atores, ativos ou passivos (HORTA et al., 1999, p. 35).

A metodologia da Educação Patrimonial procura resgatar a memória e estimular a relação de afeto entre os indivíduos, a comunidade e seus patrimônios, estabelecendo entre eles um processo de aproximação, de respeito, promovendo um sentimento de pertencimento em relação aos bens patrimoniais que fazem parte de sua história. A educação patrimonial é um instrumento de "alfabetização cultural" que possibilita ao indivíduo fazer a leitura do mundo que o rodeia, levando-o à compreensão do universo sociocultural e da trajetória histórico-temporal em que está inserido (HORTA et al, 1999).

Sendo assim, como a história é um processo, e as coisas mudam, transformam-se, deixando apenas experiências vividas, são as memórias que auxiliam a auto compreensão, que provocam as reconstruções transformando as memórias individuais em sociais, que formam o Patrimônio Cultural de cada indivíduo ou comunidade. E é este Patrimônio que é herança que construiu o presente e construirá o futuro, e a identidade individual que tem como pano de fundo a identidade coletiva. $\mathrm{O}$ patrimônio e a memória coletiva passam pelo patrimônio e memória individual, que compartilhados formam $o$ patrimônio e a memória cultural (POSSOLI, 2008).

\section{A disciplina História da Educação, a Educação Patrimonial e a formação de professores}

(...) não é só a escola, seja ela qual for, a educar, mas a vida inteira em sua plenitude, todo o platônico pantakhaú, o que nos remete à complexa relação educação-sociedade, que muitos, especialmente Marx, claramente descobriram e hoje tem dimensões mundiais. Se o fato educativo é um politikum e social, consequentemente, é também verdadeiro que toda situação política e social determina sensivelmente a educação: portanto, nenhuma batalha pedagógica pode ser separada da batalha política e social (MANACORDA, 2010, p. 432).

Em se tratando da educação escolar brasileira, muitas vezes é dada uma maior valorização às disciplinas técnicas, o que se pode observar na maioria dos planos curriculares e nos projetos pedagógicos da maioria dos cursos de formação de professores. Percebe-se que não são muito presentes as práticas pedagógicas que ampliem a compreensão de universos mais amplos de conhecimento, que tenha como foco principal o indivíduo, que ensine a partir de seus saberes e de memórias individuais e coletivas. Esse descuido priva os estudantes de licenciaturas, como sujeitos 
sociais, de viverem o passado-presente que está carregado de lições, de significados a serem ressignificados e aprendidos. Importante se faz "reconhecer a memória real como história, como impulsionadora de outra história possível" (ARROYO, 2013, p.316).

A educação patrimonial considera que a aprendizagem decorre do conhecimento da realidade concreta, do passado e do presente, de forma crítica e democratizada. Horta, Grunberg e Queiroz (1999) definem a Educação Patrimonial como:

O trabalho de Educação Patrimonial busca levar as crianças e adultos a um processo ativo de conhecimento, apropriação e valorização de sua herança cultural, capacitando-os para um melhor usufruto desses bens, e propiciando a geração e a produção de novos conhecimentos, num processo contínuo de criação cultural (HORTA; GRUNBERG; QUEIROZ, 1999, p.6).

A importância da Educação Patrimonial está no fato de favorecer uma determinada leitura do passado, uma releitura do presente e um redirecionamento do futuro; criando representações sobre fatos, saberes, culturas, lugares e obras que influenciam o desenrolar da própria história. Partindo do confronto entre passado e presente, é possível compreender o patrimônio cultural como produto do homem - sujeito da história (SILVEIRA; BONATO, 2008).

Pode-se compreender que a Educação Patrimonial, na visão dos autores supracitados, favorece a produção de um conhecimento ativo, que favorece a apropriação de saberes, que geram o entendimento da herança cultural como parte da identidade de cada pessoa.

Torna-se importante conhecer e considerar as práticas educativas que nortearam a educação durante a história, como práticas sociais, culturais e políticas arraigadas em valores, tradições e costumes, que garantiram aos sujeitos a progressiva criação de novos significados e subjetividades, a satisfação de suas expectativas e necessidades, na busca de uma melhor compreensão da realidade educacional atual que favorece a formação de professores reflexivos e conscientes.

A metodologia da Educação Patrimonial é desenvolvida em quatro etapas, sendo elas: a observação, o registro, a exploração e a apropriação do bem cultural. Espera-se identificar o objeto, sua função e significado; registrar o conhecimento percebido, através do aprofundamento da observação; desenvolver a análise crítica através da consulta a outras fontes; e a apropriação do conhecimento adquirido por meio da participação criativa (HORTA et al., 1999, p. 11).

Embora sinteticamente apresentados, estas etapas propostas pela Educação Patrimonial revelam a riqueza de habilidades, conceitos e conhecimentos que podem ser adquiridos pelos envolvidos neste processo educativo dentro de um caráter interdisciplinar que a metodologia da Educação Patrimonial possui (HORTA et al., 1999, p. 36). Os objetos patrimoniais, enquanto recursos educacionais, podem ser usados em qualquer área do currículo, ou para reunir áreas aparentemente distantes no processo ensino-aprendizagem (HORTA et al., 1999, p. 36).

A disciplina História da Educação, nos cursos de formação de professores, deve ter como objetivos proporcionar aos educadores um conhecimento coletivo da profissão e contribuir para a formação da sua cultura profissional, ampliar a sua memória e experiência, alargar o leque de opções e de possibilidades pedagógicas, fornecerlhes uma visão alargada das instituições escolares do passado e mostra-lhes que a educação é uma construção social. A História da Educação é, assim, uma disciplina que pretende favorecer o acesso a uma visão global e diacrônica da educação, considerando os sistemas educativos como pontos de chegada de uma longa e lenta evolução (MARTINHO, 2000).

A despeito de pretensões demagógicas, essa perspectiva deve ser efetivamente integrada ao cotidiano dos profissionais da educação como? A partir da abordagem de novos temas e de fontes documentais referentes ao patrimônio cultural e natural e, também, no planejamento de atividades diversificadas que possam instigá-los a revigorar o trabalho na sala de aula e a estimular seus alunos a também "redescobrirem" suas histórias, memórias, identidades para que exerçam plenamente os seus direitos à cidadania (PELEGRINI, 2009, p.43).

O ensino da História da Educação tem também como função formar a consciência histórica a fim de possibilitar a compreensão de como se dá a construção da identidade dos sujeitos, sendo que esse é um dos aspectos cruciais da formação do professor, que se retrata nas suas práticas educacionais do cotidiano. E nesse percurso a educação patrimonial tem muito a contribuir, pois favorece uma aprendizagem permeada pelo questionamento e pelo diálogo. Se a educação 
consiste em ensinar e aprender, a transmissão cultural de uma geração a outra é um elemento importante, sendo que o estudo da história permite enxergar a realidade com outros olhares, identificar culturas, educação, escolas e práticas educativas.

No ensino da história costuma-se dizer que "a história é feita com documentos", mas o que acaba acontecendo são apenas citações, imagens, fotografias, apresentadas nos livros, muitas vezes de maneira equivocada, dificultando a visão dos documentos ou fontes como bens culturais. Importante se faz saber que as fontes (objetos materiais, mensagens escritas e orais gravadas, imagens, esculturas, paisagens, arquiteturas e centros urbanos), antes de serem usadas para a produção de informação, são vestígios de atividades humanas no passado e assim devem ser analisadas e respeitadas.

Ao se tratar da educação patrimonial no contexto de formação de professores, emergem algumas questões relativas ao ensino e a conscientização desses estudantes. Ao se tratar da educação patrimonial nos estudos de História da Educação, estas questões ganham caráter mais específico, próprio da ciência histórica. Uma questão, por exemplo, é a afirmativa de que a História se utiliza do patrimônio enquanto fonte, capaz de fornecer informações do passado das sociedades sob as representações da memória coletiva. Lembrando que o patrimônio cultural, de maneira geral, e o imaterial, especificamente, podem se constituir como preciosas fontes para o ensino da História. Se o trabalho com a História da Educação se restringir apenas às informações que estão nos livros, com certeza os alunos não terão a oportunidade de "relacionar o conhecimento histórico aos vestígios graças por meio dos quais tal conhecimento foi gerado e não têm a possibilidade de se dar conta dos procedimentos de produção e uso das fontes" (MATOZZI, 2008). Sendo assim, terão dificuldade para interpretar os vestígios e fazer a ligação dos mesmos com as atividades historiográficas. Assim nos diz Matozzi (2008, p. 04):

Se quisermos honrar a promessa de utilidade do conhecimento histórico, devemos projetar e implementar processos de ensino para relacionar o conhecimento histórico às coisas consideradas bens culturais e despertar a consciência cívica em relação ao patrimônio cultural.

Outra questão, é que a Educação Patrimonial e as pesquisas na História da Educação têm a intenção de desmistificar o senso comum, fazendo com que os estudantes na área da educação, professores e outros profissionais, percebam as escolas, os documentos, as metodologias usadas, os recursos pedagógicos utilizados pelos professores, em diferentes tempos e costumes, como patrimônios culturais pertencentes a sua história profissional e formadores de identidades.

Quando falamos sobre Patrimônio Cultural, logo pensamos em monumentos, casas antigas, etc. Esta é a visão do senso comum, porém a ideia de Patrimônio é bem mais ampla, e inclui vários outros aspectos. Todas as modificações feitas por uma sociedade na paisagem para melhorar suas condições de vida, bem como todas as formas de manifestação socialmente compartilhadas, fazem parte do patrimônio, pois todo objeto ou ação que se refere à identidade de uma sociedade constitui seu patrimônio. Dessa forma, devemos deixar bem claro que patrimônio não é necessariamente tudo aquilo que determinada sociedade considera significativo no presente, mas também o que foi importante no contexto do passado. Consequentemente, não é apenas o belo, o grandioso, o heroico. Também é o corriqueiro, o cotidiano, e o simples (SOARES, 2003, p. 46).

A educação patrimonial vai além do estudo de ambientes específicos como museus ou edificações, ela lança um olhar sobre as histórias das culturas que estão presentes nos espaços e tempos mais diversificados, portanto, tem um caráter interdisciplinar com a História da Educação, que deve ir além das datas e descrição de fatos, mas que deve buscar resgatar as práticas educacionais ao longo do tempo, provocando aprendizados, vivências, socialização, conscientização de identidade cultural e de responsabilidade com o social, além de desenvolver habilidades que instiguem uma leitura crítica da educação no passado e no presente. As memórias e referências do passado fundamentam, por um lado, a coesão entre os indivíduos que compartilham afetos, sensibilidades, tradições e histórias (PELEGRINI, 2009).

Se por muito tempo o conceito de patrimônio ficou restrito aos bens materiais, hoje essa noção se amplia para abranger o patrimônio cultural, que engloba aspectos históricos, ecológicos, artísticos e científicos, incluindo o patrimônio documental e arquivístico, bibliográfico, hemerográfico, iconográfico, oral, visual, museológico, enfim, todo conjunto de bens que 
atestam a história de uma dada sociedade.

A discussão sobre patrimônio tem avançado nas últimas décadas, na medida em que se concebe que objetos, espaços, conhecimentos e manifestações tornam-se "patrimônio imaterial" porque tem valor referencial para a comunidade. Considera-se que as referências patrimoniais são aos objetos Constitutivos da memória da formação, formas de trabalho e vida passadas ou atuais. De todo modo, o patrimônio apresenta-se como a materialização de um discurso sobre o passado (OLIVEIRA, 2010, p. 133).

Quando os objetos são usados para a construção de conhecimento sobre o passado, deixando de serem apenas instigadores de saudosismos festivos e exaltações, tornam-se um fenômeno que provoca o pensamento e a ação sobre o mundo, tornam-se patrimônio cultural, que deve ser preservado, protegido e posto em exposição. Por um motivo maior, os objetos transformam-se em bens culturais caso tenham sido reconhecidos como produtores de emoções estéticas e investimentos afetivos (MATOZZI, 2008).

As fontes da história de uma escola instituem seu patrimônio e são fundamentais nos estudos da História da Educação. Todos os registros documentais como diários de professoras, cartilhas, livros didáticos, material escolar, arquitetura do prédio escolar, bibliotecas, exercícios, provas, convites de formatura, hinos da escola, livros de ocorrência, memórias de alunos, professores e funcionários de escola, periódicos escolares e estudantis, escritas epistolares, fotografias, mobiliário, uniformes, entre outros, fornecem a quem pesquisa indícios de práticas escolares, que permitem inferir acerca dos métodos de ensino, da disciplina, do currículo, dos saberes escolares, da formação de professores, enfim, revelam um pouco da história das instituições. (CHAVES, 2013). Todo o conjunto de traços, de documentos sobre o passado, inclui, ainda, dependendo do período histórico a ser estudado, o trato com a história oral, com a pesquisa junto a pessoas que fizeram parte da construção das práticas pedagógicas do ensino realizadas noutros tempos.

A equação para compreendermos as relações e distinções entre memória, patrimônio e história é complexa. Ao se fazer história, basicamente se historiciza patrimônio, haja vista serem as memórias que constituem o patrimônio material e imaterial - e que compõem os lugares da memória, os monumentos, os documentos/fontes para produção histórica. Portanto, ao se produzir/ensinar história, necessariamente estuda-se patrimônio. Por esse prisma, patrimônio não é história, é documento (CHAVES, 2013, p. 63).

Os patrimônios da escola traduzem o cotidiano da escola e mostram indícios de saberes e de práticas escolares, o que contribui muito para os pesquisadores da História da Educação, para a própria história, para a memória da instituição, possibilitando a compreensão sobre a cultura escolar de outros tempos e assim compreender quais princípios regem a cultura escolar da atualidade. Memória como sendo elemento constituinte da identidade individual e coletiva. Relacionada às culturas e aos modos de entender o mundo, essencial para a continuidade das práticas culturais e para a reconstrução de si (PELEGRINI, 2009).

Portanto, a consciência histórica, no contexto da História da Educação e da educação patrimonial, enquanto um processo de formação e/ou reconhecimento da identidade, ajuda o professor a formular interpretações sobre si e sobre a educação no tempo, sobre os saberes, crenças e práticas educativas que fazem parte dos contextos históricos e sociais remotos e que se e evidenciam nas práticas cotidianas dos dias atuais. Os bens culturais produzidos na escola e fora dela constituem material precioso para a análise de como a educação é pensada em diferentes momentos históricos e de que modo se busca ordenar a sua prática.

\section{Considerações finais}

Apesar de o homem lhe parecer, por natureza e de fato, unilateral, eduque-o com todo empenho, em qualquer parte do mundo, para que se torne unilateral (MANACORDA, 2010, p. 437).

As discussões expostas neste artigo mostram os pontos de contato entre o ensino da História da Educação e a Educação Patrimonial no contexto da formação de professores. Pode-se perceber que as interações estabelecidas no ensino de História da Educação com a Educação Patrimonial revelam certa interdependência que possibilitam um ensino transformador $\mathrm{e}$ diversificado. Pode-se chegar à reflexão que tanto a educação histórica como a educação patrimonial priorizam uma aprendizagem com base na 
formação de uma consciência histórica e cultural, com vistas à construção de identidades individuais e sociais, sabendo que o conhecimento é obtido à medida que os alunos estabelecem relações com os fatos do passado em um contexto mais amplo e diversificado.

O uso dos princípios e da metodologia da Educação Patrimonial no ensino da História da educação mostra-se eficaz no contexto de formação de professores, já que desmistifica o senso comum e propõe um ensino por meio de fontes e patrimônios históricos, onde o patrimônio surge como formas de um passado inacabado e aberto aos significados sociais que são coadjuvantes no processo de formação de identidades individuais e sociais.

\section{Referências}

ARROYO, M. Currículo, território em disputa. Rio de Janeiro: Vozes, 2013.

CHAVES, E. O. Educação patrimonial e ensino de história: potenciais do uso de documentação arquivística. História \& Ensino, Londrina, v. 19, n. 2, p. 59-85, jul./dez. 2013. Disponível em file:///C:/Documents\%20and\%20Settings/X/Meus \%20documentos/Downloads/16116-73604-1PB\%20(3).pdf. , acesso em 15 de junho de 2014.

FREIRE, P. Educação e Mudança. São Paulo: Paz e Terra, 1991.

HORTA, M. L. P.; GRUNBERG, E.; MONTEIRO, A. Q. Guia básico de educação patrimonial. Brasília: Instituto do Patrimônio Histórico e Artístico Nacional, Museu Imperial, 1999.

LOPES, V. V. Memória, história e história oral. Revista Eletrônica História, Educação \& Tecnologias. v. 1, $\mathrm{n}^{\mathrm{o}} 2$, p. s/n. 2012. Disponível em http://hetec.wordpress.com/219-2/, acesso em 24 de maio de 2014.

MANACORDA, M. A. História da Educação: da
Antiguidade aos nossos dias. São Paulo: Editora Cortez, 2010.

MARTINHO, A. M. M. A História da Educação na formação de professores. Máthesis. v. 9, 2000, p. 279-296. Disponível em http://www4.crb.ucp.pt/biblioteca/mathesis/mat9/ mathesis9_279.pdf, acesso em 13 de junho de 2014.

MATOZZI, I. Didática da História e Educação para o patrimônio. Disponível em http://revistaescola.abril.com.br/fundamental2/didatica-historia-educacao-patrimonio-fonteshistoricas-753032.shtml, acesso em 12 out 2014.

OLIVEIRA, E. R. Memória, história e patrimônio Perspectivas contemporâneas da pesquisa histórica. Fronteiras. v. 12, n. 22, p. 131-151, jul./dez. 2010. Disponível $\mathrm{em}$ http://www.periodicos.ufgd.edu.br/index.php/FRO NTEIRAS/article/viewFile/1184/728, acesso em 30 de maio de 2014.

PELEGRINI, S.C.A. Patrimônio Cultural: consciência e preservação, São Paulo, Editora Brasiliense, 2009.

POSSOLI, T. A importância da educação patrimonial: a CSN como patrimônio histórico em Siderópolis. Monografia. Universidade do Extremo Sul Catarinense- UNESC. 2008. Disponível em http://www.bib.unesc.net/biblioteca/sumario/00003 8/00003826.pdf, acesso em 02 de junho de 2014.

SILVEIRA, L. A.; BONATO, N. M. C. Educação \& Cidade: o papel da escola na preservação do patrimônio cultural. IV Encontro Nacional da Anppas, 2008. Disponível em http://www.anppas.org.br/encontro4/cd/ARQUIVO S/GT8-1069-1031-20080510222854.pdf, acesso em 12 de junho de 2010.

SOARES, A. L. R. Projeto de Educação Patrimonial: Retrospectivas e Possibilidades. In: SOARES, A. L. R. et al. (org). Educação Patrimonial: relatos e experiências. Santa Maria: UFSM, 2003, p.109-114. 


\section{Sobre a autora}

Claudia Maria Soares Rossi é Pedagoga, Mestre em Educação pela Universidade Federal de Lavras. Especialista em Didática e Metodologia do Ensino, Psicopedagogia e Inspeção Escolar. Professora, Técnica em Assuntos Educacionais do Instituto Federal de Educação de Minas Gerais.

Recebido em janeiro de 2015.

Aprovado em maio de 2016. 